\title{
STRUCTURE-PROPERTY RELATIONSHIPS IN WASPALOY VIA SMALL ANGLE SCATTERING AND ELECTRICAL RESISTIVITY MEASUREMENTS
}

\author{
Ricky L. Whelchel ${ }^{1}$, Rosario A. Gerhardt ${ }^{1, *}$, and Ken Littrell $^{2}$ \\ ${ }^{1}$ School of Materials Science and Engineering, Georgia Institute of Technology; \\ 771 Ferst Drive; Atlanta, GA 30332, USA. \\ ${ }^{2}$ High Flux Isotope Reactor, Oak Ridge National Laboratory; \\ PO Box 2008 MS6393; Oak Ridge, TN 37831, USA.
}

Keywords: Small Angle Scattering, Electrical Resistivity, Non-destructive Testing, Waspaloy

\begin{abstract}
Particle size distributions of $\gamma^{\prime}$ phase were obtained for Waspaloy specimens aged at $725^{\circ} \mathrm{C}$ and $800^{\circ} \mathrm{C}$ for times ranging from $120 \mathrm{~s}$ to approximately $1 \times 10^{6} \mathrm{~s}$ through fitting small angle neutron scattering (SANS) spectra with a volume distribution of spherical precipitates. The average precipitate radius is found to increase progressively with both aging time and temperature. Electrical resistivity measurements for the aged Waspaloy specimens show an initial increase reaching a maximum at short aging times, followed by a decrease in resistivity with increasing aging time after the resistivity peak. The electrical response was modeled utilizing a microstructural model that accounts for conduction electron scattering from both precipitates and solute atoms. The microstructural model shows a good fit to the measured electrical resistivity, indicating its validity for predicting the electrical response in aged Waspaloy. These results suggest that the electrical response due to aging may be used to quantitatively obtain precipitate microstructural information in Waspaloy in a non-destructive fashion.
\end{abstract}

\section{Introduction}

Nickel-base superalloys, such as Waspaloy, are the predominant materials used in the hot sections of gas turbine engines. Superalloys are ideal for this purpose due to their superior high temperature properties, which are possible as a result of the presence of nanometer-scale precipitate phases induced via proper heat treatments. These precipitates, known as $\gamma^{\prime}$ in Waspaloy, greatly impede the motion of dislocations throughout the microstructure in superalloys, resulting in the increased high temperature strength and creep resistance common to gas turbine engine components. The precipitate microstructure is induced within these components prior to their service; however, the initial precipitate microstructure can evolve with thermal exposure in gas turbine engines, resulting in a corresponding change in the mechanical properties. In order to track this change in mechanical properties, non-destructive techniques for monitoring the evolution of the precipitate microstructure due to heat treatment are needed.

DC electrical resistivity measurements provide a non-destructive method for monitoring the precipitate population in superalloys. Specifically, electrical resistivity is sensitive to the nucleation of small precipitates, the increase in precipitate size and spacing associated with 
growth and coarsening, and the removal of precipitate phase solute from the matrix phase [1-6]. It was shown for Nimonic alloy PE16 that during the initial stages of aging, the nucleation of small precipitates $(<1 \mathrm{~nm})$ causes a significant increase in conduction electron scattering over that of the initial solutionized specimen [6]. A similar observation was made for 7012 aluminum, and this increasing resistivity region has been modeled with a Johnson-Mehl-Avrami (JMA) type equation [7]. The JMA behavior was associated with the increase in the volume fraction of GP zones in this alloy. Unfortunately, this model does not predict electrical resistivity behavior past the initial maximum in resistivity. Since gas turbine engine components are age-hardened well past this resistivity peak prior to service, it is desirable to model the resistivity behavior for much longer aging times. Such a model for resistivity has been recently suggested, whereby the changes in precipitate size, spacing, volume fraction, and matrix solute content are considered [2, $4,5]$. This allows for the more complex microstructural changes associated with the growth and coarsening of the $\gamma^{\prime}$ precipitates to be included within the electrical response model.

Small angle scattering (SAS) techniques, such as small angle X-ray scattering (SAXS) and small angle neutron scattering (SANS), are among the methods by which the precipitate microstructure can be quantitatively analyzed in nickel-base superalloys [2, 4, 5, 8-10]. SAS techniques are useful, as the measurement is taken throughout the sample volume of interest. SANS measurements are particularly well-suited for nickel-base superalloy specimens as nickel is highly absorbing of X-rays. Neutrons, on the other hand, are highly penetrating allowing for thick (mm scale) slices to be measured. Fitting of SAS spectra can provide a volume distribution of particle sizes, provided that the precipitate morphology and the chemistry of the particles and matrix are known [11]. In fact, volume distributions of $\gamma^{\prime}$ precipitates in Waspaloy have been obtained from SAS data for a variety of heat treatment conditions [2, 4, 5]. The microstructural information obtained from SAS modeling can be used in the creation of structure-property relationships for monitoring the evolving microstructure via non-destructive type analysis techniques.

In this paper, small angle neutron scattering spectra obtained from Waspaloy specimens aged at $725^{\circ} \mathrm{C}$ and $800^{\circ} \mathrm{C}$ were fit with a volume distribution of spherical precipitates. The fitted volume distributions were used in the calculation of a microstructural model for the expected electrical response as a function of aging time. The microstructural model was compared to the actual measured resistivity, showing the effectiveness of the model for predicting electrical trends with aging time in Waspaloy.

\section{Procedure}

\section{$\underline{\text { Heat Treatments }}$}

Bulk Waspaloy bars (13 mm in diameter) were obtained from Fry Steel. The approximate composition of the Waspaloy bars is as follows (in at\%: Ni 56.1, $\mathrm{Cr} 21.2$, Co 12.3, Ti 3.6, $\mathrm{Al} \mathrm{2.7,}$ Mo 2.5 and Fe 1.3). The Waspaloy bars were solution treated at $1145^{\circ} \mathrm{C}$ for 4 hours and quenched in a $\sim 5 \mathrm{wt} \%$ brine solution. The solution treated bars were sectioned into approximately $8 \mathrm{~mm}$ sections, and these sections were aged at $725^{\circ} \mathrm{C}$ and $800^{\circ} \mathrm{C}$ for times ranging from $120 \mathrm{~s}$ to approximately $1 \times 10^{6} \mathrm{~s}$ followed by a second quench. All aging times used for this study are listed in Table I. The age hardened sections were further sectioned into approximately $2 \mathrm{~mm}$ thick samples for subsequent microscopy, small angle neutron scattering (SANS), and electrical resistivity testing. 
Table I. Aging times used for the Waspaloy specimens heat treated at both $725^{\circ} \mathrm{C}$ and $800^{\circ} \mathrm{C}$. The aging times are listed in both minutes/hours and seconds for clarity.

\begin{tabular}{|l|cccccc|}
\hline Aging Time (s) & $1.2 \times 10^{2}$ & $3.6 \times 10^{2}$ & $1.08 \times 10^{3}$ & $1.8 \times 10^{3}$ & $5.4 \times 10^{3}$ & $1.26 \times 10^{4}$ \\
\hline Aging Time (min) & 2 & 6 & 18 & 30 & 90 & 210 \\
\hline Aging Time (s) & $3.06 \times 10^{4}$ & $6.66 \times 10^{4}$ & $1.386 \times 10^{5}$ & $3.186 \times 10^{5}$ & $5.886 \times 10^{5}$ & $9.486 \times 10^{5}$ \\
\hline Aging Time (h) & 8.5 & 18.5 & 38.5 & 88.5 & 163.5 & 263.5 \\
\hline
\end{tabular}

\section{Microscopy}

Specimens for microscopic observations were ground with 400 US grit SiC grinding papers, followed by polishing with $9 \mu \mathrm{m}$ and $3 \mu \mathrm{m}$ diamond polishing solutions. Fine polishing was performed using a suspension of 4 parts of $0.05 \mu \mathrm{m}$ colloidal silica mixed with 1 part $\mathrm{H}_{2} \mathrm{O}_{2}$ followed by polishing with a suspension of $0.05 \mu \mathrm{m}$ alumina. Specimens for microstructural imaging were electrolytically etched with a preferential matrix $(\gamma)$ etchant, allowing for observation of $\gamma-\gamma^{\prime}$ contrast [3]. This etchant consisted of 2 parts methanol and 1 part $\mathrm{HNO}_{3}$ at room temperature. The specimens were immersed in the solution for approximately $30 \mathrm{~s}$ along with the application of 50V DC from a Keithley 228A voltage/current source. Microstructural images were obtained using a Park Systems XE-100E atomic force microscope (AFM) in noncontact mode. Specimens for energy dispersive spectroscopy (EDS) measurements were exposed to a preferential $\gamma^{\prime}$ etchant, consisting of $10 \mathrm{ml}$ each of $\mathrm{HCl}, \mathrm{HNO}_{3}, \mathrm{H}_{2} \mathrm{O}$ and $0.3 \mathrm{~g}$ of molybdic acid reagent. EDS measurements were obtained using a LEO 1530 scanning electron microscope.

\section{$\underline{\text { Small Angle Neutron Scattering }}$}

Specimens for SANS studies were ground with a series of 400, 800, and $1200 \mathrm{SiC}$ US grit grinding papers. SANS measurements were performed at the High Flux Isotope Reactor on the CG-2 beamline at Oak Ridge National Laboratory. This beamline has a cold neutron source with a $1 \mathrm{~m}^{2}$ area detector with $5 \times 5 \mathrm{~mm}^{2}$ pixel resolution. The measurements were obtained with three different instrument configurations, resulting in data obtained for three different scattering vector (Q) ranges. The high and medium $Q$ ranges were obtained with a source to sample distance of $9.229 \mathrm{~m}$ and a wavelength of $4.75 \AA$. The sample to detector distances for the high and medium $\mathrm{Q}$ ranges were $1.161 \mathrm{~m}$ and $8.861 \mathrm{~m}$ respectively. The low $\mathrm{Q}$ region was obtained with a source to sample distance of $17.275 \mathrm{~m}$, a sample to detector distance of $19.361 \mathrm{~m}$, and a wavelength of $12 \AA$. The scattering intensity was azimuthally averaged as a function of $Q$ for each instrument configuration, yielding an entire Q range of approximately $10^{-3} \AA^{-1}$ to $1 \AA^{-1}$.

All data reduction and modeling was performed using the Igor Pro software from Wavemetrics, Inc. Data reduction was performed using the Spice SANS reduction package [12], whereas data modeling was conducted using the Irena package [11]. Both of these packages were created for modeling and analysis of SAS data within the Igor Pro software[11,12]. The SANS spectra were fitted to obtain volume distributions of spherical particle sizes using a hard sphere 
model for the structure factor and a spherical form factor. These assumptions are accurate as the $\gamma^{\prime}$ precipitates are known to be spherical in this alloy [1-5]. The equations for the structure factor and form factor used in the current study are presented in great detail by Ilavsky and Jemian [11]. Specimens exposed to a preferential $\gamma^{\prime}$ etchant were used to calculate the $\gamma$ - $\gamma^{\prime}$ scattering contrast from EDS measurements. The composition of the matrix phase as measured by EDS is given nominally as $\mathrm{Ni}_{0.607} \mathrm{Cr}_{0.2304} \mathrm{Co}_{0.135} \mathrm{Mo}_{0.028}$, whereas the composition of the precipitate phase was assumed to be $\mathrm{Ni}_{3} \mathrm{Ti}_{0.5} \mathrm{Al}_{0.5}$ since the chemical formula for $\gamma$ ' in Waspaloy is $\mathrm{Ni}_{3}(\mathrm{Al}, \mathrm{Ti})$.

\section{$\underline{\text { Electrical Resistivity Testing }}$}

Specimens used for electrical resistivity measurements were prepared in a similar fashion as the microscopy specimens. DC four-point probe resistivity testing was performed via a Signatone model S301-6 probe station attached to a Signatone SP4-40045TFS four probe head along different diametric orientations of each sample. Current was applied using the delta mode setting of a Keithley $6221 \mathrm{AC} / \mathrm{DC}$ current source, and voltage measurements were obtained using a Keithley 2182A nanovoltmeter. This yielded resistance values that were subsequently converted to resistivity values via proper geometric correction factors [13].

\section{Results And Discussion}

\section{$\underline{\text { Microscopy }}$}

A representative microstructural image of the $\gamma^{\prime}$ precipitate microstructure after aging at $725^{\circ} \mathrm{C}$ for $1.26 \times 10^{4} \mathrm{~s}$ is shown in Figure 1. Since a preferential matrix etchant was utilized, the $\gamma^{\prime}$ precipitates appear as upraised spheres in Figure 1. The precipitate sizes and their relative spacing increased with increasing aging time, and the precipitates remained spherical throughout all aging times, as assumed for SANS modeling.

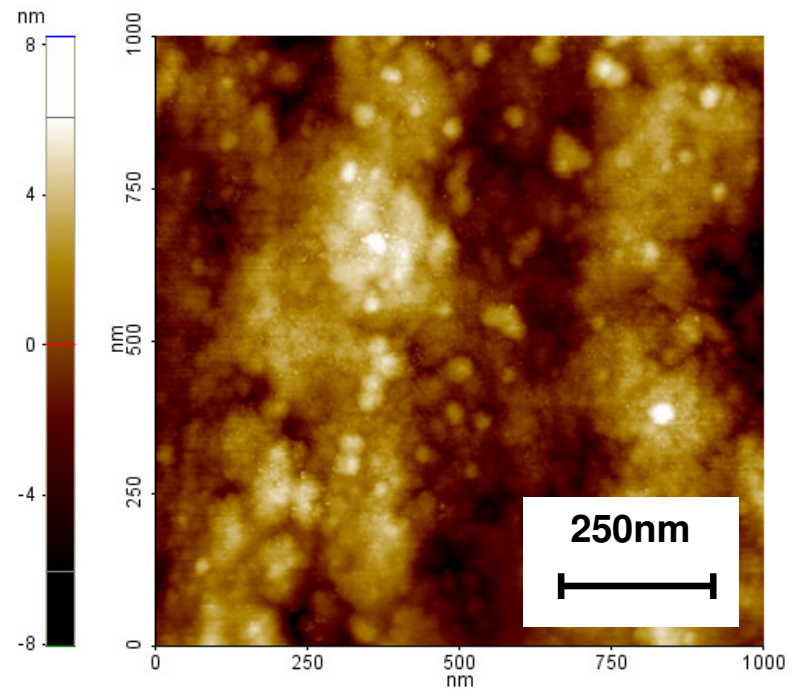

Figure 1. AFM topography image of the $\gamma^{\prime}$ precipitate phase due to aging at $725^{\circ} \mathrm{C}$ for $1.26 \times 10^{4} \mathrm{~s}$

\section{$\underline{\text { Small Angle Neutron Scattering }}$}


The SANS spectra for aging at $725^{\circ} \mathrm{C}$ and $800^{\circ} \mathrm{C}$ for various aging times are presented in Figure 2: in order to make the data more readable, only selected spectra are shown.
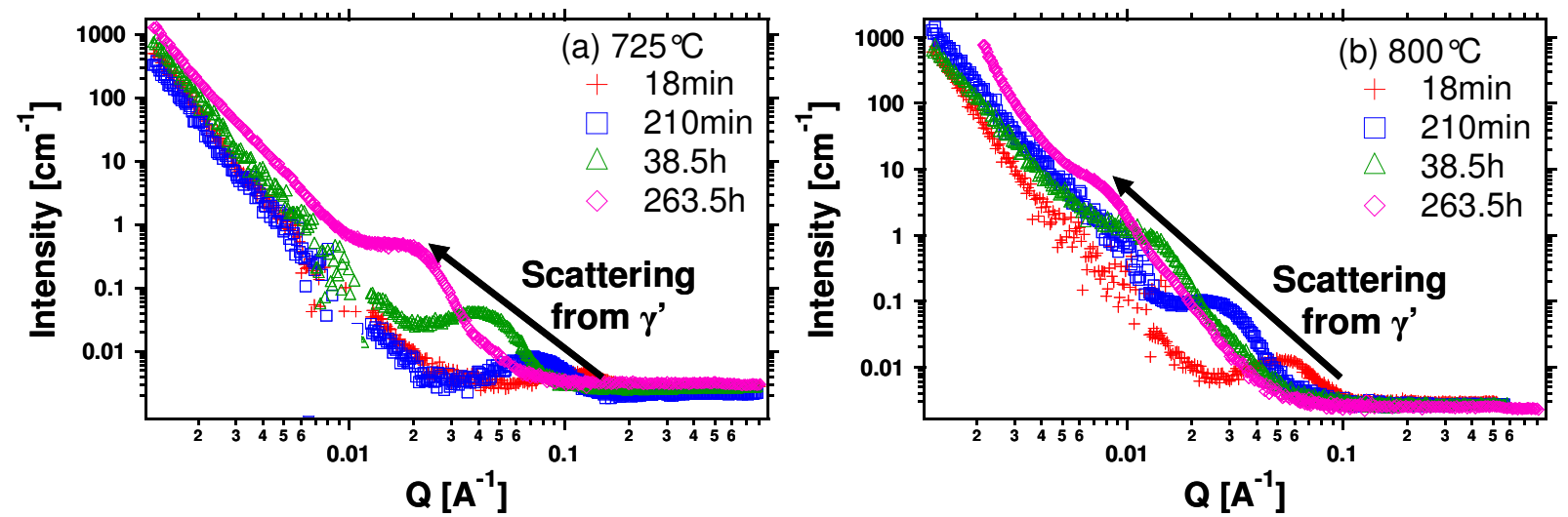

Figure 2. Selected SANS spectra for Waspaloy specimens aged at (a) $725^{\circ} \mathrm{C}$ and (b) $800^{\circ} \mathrm{C}$ for various aging times. Arrows indicate the shift in the scattering region due to the coarsening of $\gamma^{\prime}$ precipitates.

The scattering region for $\gamma^{\prime}$ ranges between $Q$ values of 0.005 and $0.2 \AA^{-1}$. The linear-like region (for the log-log axes used) at very low $\mathrm{Q}\left(<0.005 \AA^{-1}\right)$ may be attributed to scattering from larger scattering objects, such as carbides, since the scattering vector is inversely proportional to the size of the scattering object. For both aging temperatures examined, the $\gamma^{\prime}$ scattering region shifts to lower values of $\mathrm{Q}$ with aging time, indicating the increase in the size of the precipitates due to heat treatment. The precipitate scattering regions for samples aged at short aging times show a peak-like function. This peaked scattering region is known as a correlation peak and indicates inter-particle scattering from closely spaced precipitates [14]. At longer aging times, the peak begins to disappear indicating a decrease in inter-particle scattering from an increasing $\gamma$ ' nearest neighbor distance.

\section{$\underline{\text { Microstructural Information From SANS }}$}

SANS spectra, like those presented in Figure 2, were fit to obtain volume distributions of spherical precipitates. The derived particle size distributions of the $\gamma$ ' phase (PSD's) are shown in Figure 3 and display the evolution in the precipitate microstructure with aging. For the samples aged at $725^{\circ} \mathrm{C}$ for the two shortest aging times, there was no significant scattering region; therefore, no PSD's were obtained for those samples.

It may be noted in Figure 3 that for both aging temperatures, the $\gamma^{\prime}$ precipitates exhibit very narrow distributions at the initial aging times. With continued aging the PSD's shift to larger diameters and they broaden significantly, which is a typical coarsening behavior during aging. Moreover, the PSD's for aging at $800^{\circ} \mathrm{C}$ are shifted to larger diameters than the PSD's for aging at $725^{\circ} \mathrm{C}$ for all cases, which is attributed to the faster rate of diffusion at the higher temperature. 


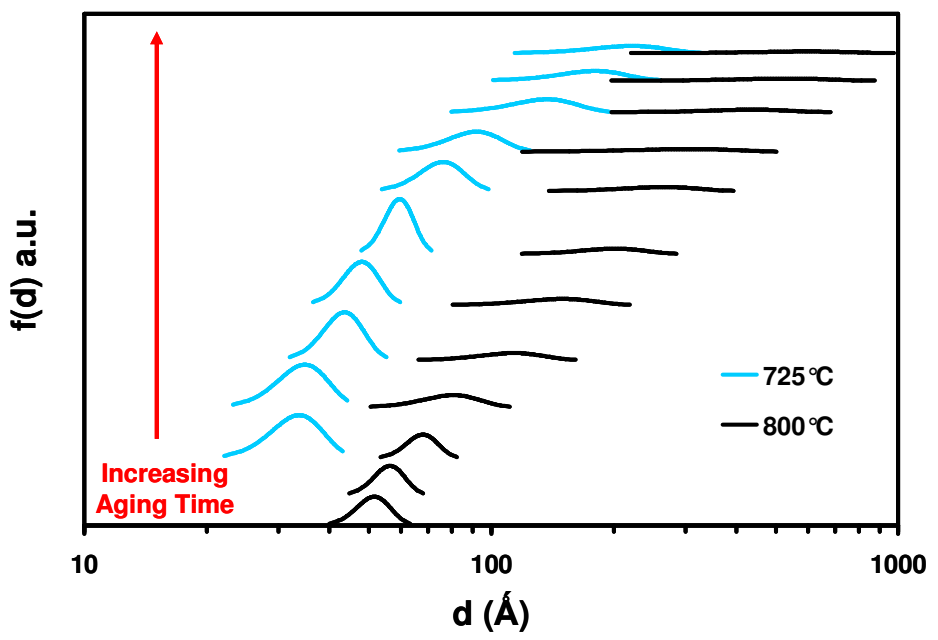

Figure 3. Particle size distributions obtained from fitting of the SANS spectra from Waspaloy specimens aged at $725^{\circ} \mathrm{C}$ and $800^{\circ} \mathrm{C}$. Each consecutive aging time has been shifted upwards for increased readability.

Figure 4a shows the change of the average precipitate radius $(<\mathrm{r}>)$ with aging time obtained from the PSD's shown in Figure 3. Figure 4b shows the coarsening behavior of the average precipitate radii through a plot of \langle\rangle$^{3}$ versus time. The error bars are derived from the full width at half the maximum of the PSD's.

Figure 4a reiterates the progressive increase in precipitate size with both aging time and temperature that was shown in Figures 2 and 3. The average radii range from $1.7 \mathrm{~nm}$ for the shortest aging time at $725^{\circ} \mathrm{C}$ to $29.9 \mathrm{~nm}$ for the longest aging time at $800^{\circ} \mathrm{C}$. Figure $4 \mathrm{~b}$ displays the expected $t^{1 / 3}$ temporal power law behavior for the precipitate radii, indicating diffusion controlled coarsening.
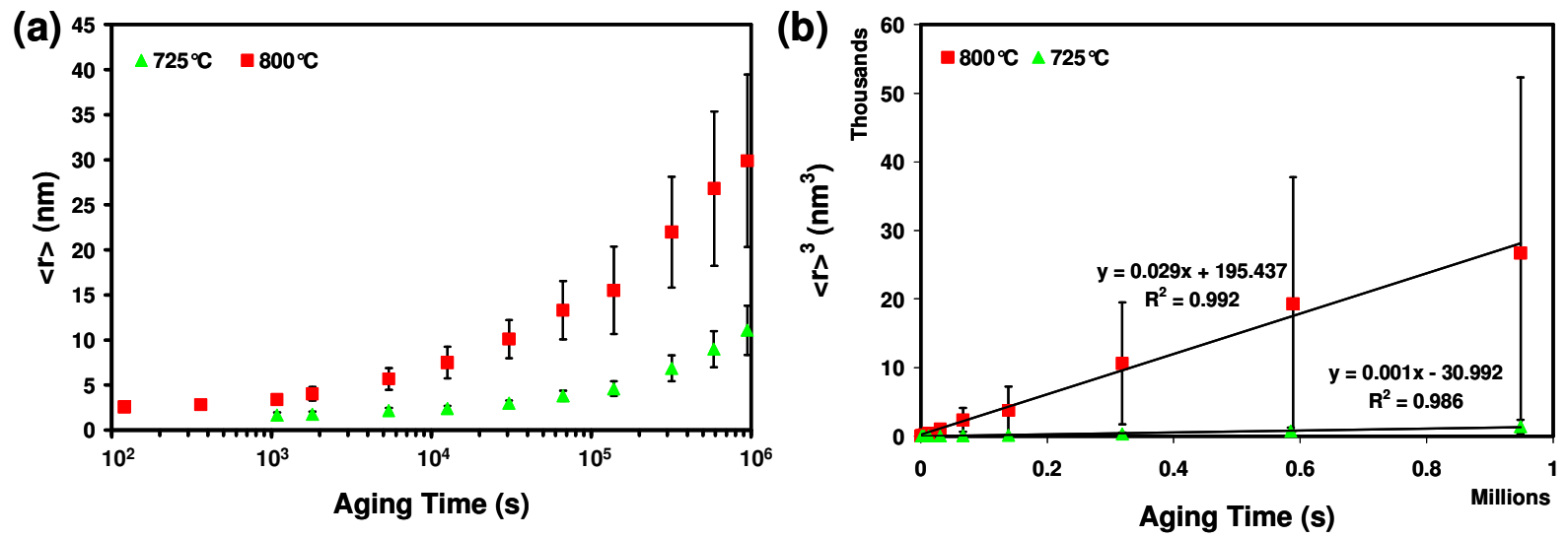

Figure 4. Change of average precipitate radii $(<\mathrm{r}>)$ with aging time for Waspaloy specimens aged at $725^{\circ} \mathrm{C}$ and $800^{\circ} \mathrm{C}$. The data is presented as (a) $<\mathrm{r}>$ versus time (on a logarithmic scale) and (b) $<r>^{3}$ versus time (on a linear scale). Linear fits are shown for the $\left\langle\mathrm{r}>^{3}\right.$ versus time data. 
Microstructural Modeling of Electrical Behavior

The measured electrical resistivity ( $\rho$ ) behavior of the Waspaloy specimens due to aging at $725^{\circ} \mathrm{C}$ and $800^{\circ} \mathrm{C}$ is shown in Figure 5. The data points at $1 \mathrm{~s}$ represent the resistivity of the solution treated specimens.

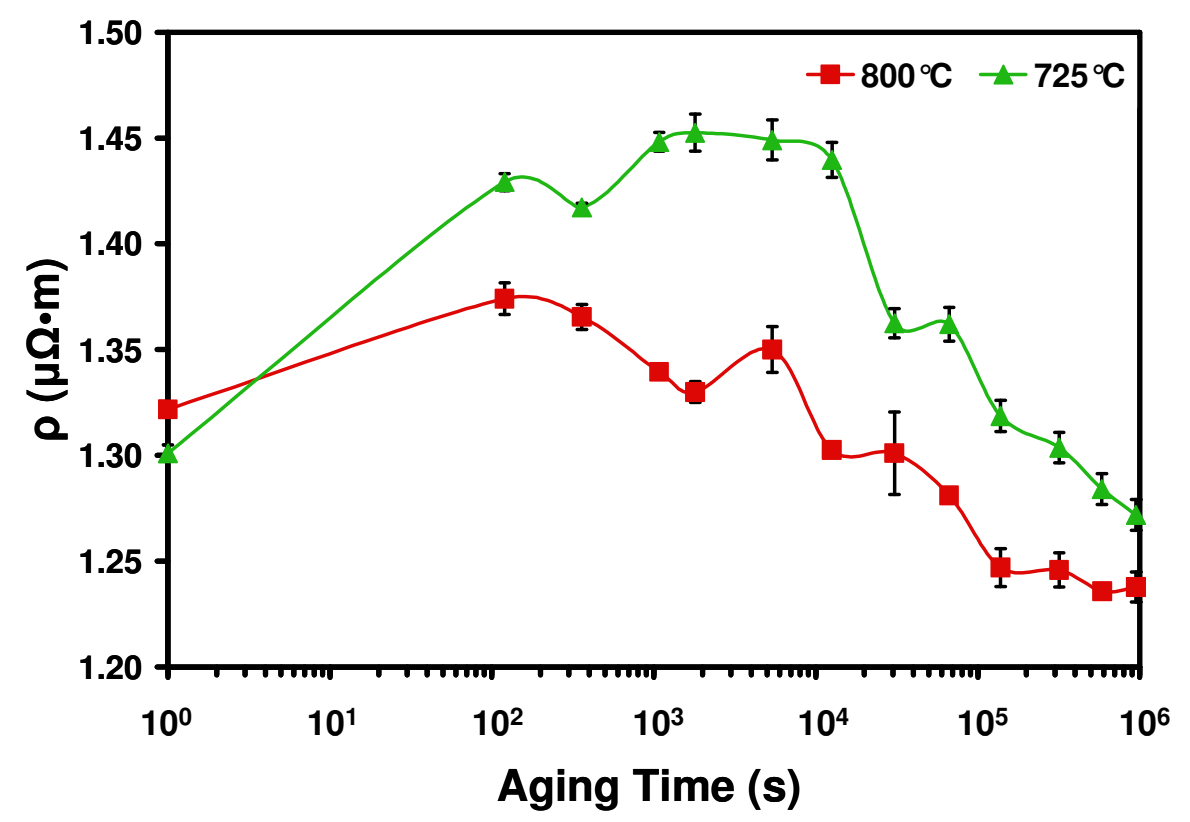

Figure 5. Measured electrical resistivity as a function of aging time for Waspaloy specimens aged at $725^{\circ} \mathrm{C}$ and $800^{\circ} \mathrm{C}$

It may be seen in Figure 5 that the electrical resistivity curves increase at the initial aging times, and then reach a maximum in resistivity, followed by a gradual resistivity decrease to values below that of the solution treated specimens. The maximum is reached at shorter aging times for aging at the higher temperature of $800^{\circ} \mathrm{C}$. The initial resistivity increase is attributable to the fast nucleation of small, closely spaced precipitates. On the other hand, the decreasing trend is due to changes in the size and spacing of the precipitates as well as solute atoms being removed from the matrix phase due to precipitation.

The microstructural model to be presented in this paper accounts for changes to an agehardened material's resistivity due to corresponding changes to the frequency of conduction electron scattering from precipitates and from solute atoms. A detailed derivation of all aspects of this model is available elsewhere $[2,4,5]$, but for clarity a short explanation of the model will be presented. The frequency of conduction electron scattering from precipitates should increase as the surface area per unit volume $\left(\mathrm{S}_{\mathrm{V}}\right)$ of the precipitates increases; however, such scattering events should decrease in frequency with increasing precipitate nearest neighbor distance $(\Delta)$, due to an increase in a conduction electron's mean free path through the material. Therefore, a figure of merit that accounts for changes in the precipitate microstructural geometry on the electrical response can be defined by equation 1 [2]. This figure of merit is designated as $\eta_{\mathrm{g}}$. 


$$
\eta_{g} \equiv \frac{S_{V}}{\Delta}
$$

For a uniform random distribution of point particles, $\Delta$ is given by equation 2 , where $\mathrm{N}_{\mathrm{V}}$ is the number density of particles [15].

$$
\Delta=0.554 N_{V}^{-1 / 3}
$$

Assuming spherical particle morphology, as is expected for Waspaloy, $\eta_{\mathrm{g}}$ reduces to that given by equation 3 , for a single distribution of precipitates [2]. The variable, $f_{V}$, is the precipitate volume fraction.

$$
\eta_{g}=3.33 \frac{f_{V}^{4 / 3}}{<r\rangle^{2}}
$$

Equation 3 only accounts for conduction electron scattering from precipitates. A complete microstructural resistivity model must also account for conduction electron scattering from solute atoms in the matrix phase. To account for these scattering events, the matrix phase by itself is considered to be a complete solid solution containing all of the alloying elements of the bulk Waspaloy material. According to Matthiessen's rule, pure metals will display the lowest resistivities, whereas, the addition of solute atoms to the solid solution results in increasing resistivity. From a microstructural standpoint, increases in the precipitate volume fraction arise from drawing precipitate phase solute atoms out of the matrix phase, thus decreasing the resistivity of the matrix. This does not imply that the resistivity of the entire material decreases progressively with increasing precipitate volume fraction. The total material resistivity is a function of the competing mechanisms of conduction electron scattering from the precipitates themselves and the decreased conduction electron scattering in the matrix as the precipitate volume fraction increases.

To quantify the changes in matrix solute content on the conduction electron scattering behavior of the entire microstructure, it is necessary to know the resistivity behavior of the matrix as a function of composition. The composition of the matrix is in turn determined by the precipitate volume fraction. For a binary metallic system in complete solid solution the resistivity behavior is often parabolic with composition; however, Waspaloy is a complex system containing several alloying elements. It is to be expected that the resistivity behavior will vary depending on which alloying elements diffuse the fastest. This is in turn determined by the aging temperature. Unfortunately, the resistivity of the matrix alone cannot be determined experimentally, since the $\gamma^{\prime}$ precipitates cannot be completely removed from the material while leaving the matrix phase intact.

To avoid this issue, an empirical model has been recently proposed $[4,5]$ that accounts for the matrix resistivity behavior as a function of volume fraction. This compositional figure of merit $\left(\eta_{c}\right)$ added to the geometrical figure of merit $\left(\eta_{\mathrm{g}}\right)$ given by equation 3 yields a model for conduction electron scattering from both precipitates and solute atoms. This compositional figure of merit is given by equation 4 [5].

$$
\eta_{c} \equiv-C f_{V}^{n}
$$


Equation 4 has positive fitting constants, $\mathrm{C}$ and $\mathrm{n}$, that can be fit to the electrical resistivity behavior after the geometrical effects on conduction electron scattering have been accounted for. Equation 4 is negative since all increases in volume fraction should decrease the frequency of conduction electron scattering events in the matrix.

The microstructural model for the conduction electron scattering ability of the entire microstructure (precipitates and matrix) is designated as $\eta$ ' and is given by equation 5 [5]. Equation 5 is normalized by the absolute value of the numerator maximum to yield a unit-less value. Equation 5 approaches infinity during nucleation due to the small initial precipitate size $(<$ $1 \mathrm{~nm})$. This continual increase in resistivity as the precipitate size decreases is not a physical behavior in age hardening systems. Therefore equation 5 is only useful for modeling the resistivity after the initial maximum. For aging times before the maximum, the method given by Ferragut et al. [7] may be used to model the electrical behavior.

$$
\eta^{\prime} \equiv \frac{\eta_{g}+\eta_{c}}{\left|\eta_{\max }\right|}=\frac{3.33 \frac{f_{V}^{4 / 3}}{<r>^{2}}-C f_{V}^{n}}{\left|\eta_{\max }\right|}
$$

The constants $\mathrm{C}$ and $\mathrm{n}$ may be varied to yield a fit of the reduced resistivity ( $\left.\rho_{\text {red }}\right)$, given by equation 6 .

$$
\rho_{\text {red }} \equiv \frac{\rho_{i}-\rho_{S T}}{\rho_{\max }-\rho_{S T}}
$$

In equation 6 , the variables $\rho_{\mathrm{i}}, \rho_{\mathrm{ST}}$, and $\rho_{\max }$ are the measured resistivities of the aged specimens, the resistivity of the solution treated sample, and the maximum value of the resistivity respectively.

The resistivities presented in Figure 5 were converted to reduced resistivities using equation 6, and are presented in Figure 6. The reduced resistivities were fit employing non-linear least squares regression with the $\eta$ ' microstructural model given by equation 5 . The $\eta$ ' fits are included in Figure 6, along with the fitting parameters $C$ and $n$. The average precipitate radii and volume fractions required for equation 5 were obtained from the PSD's presented in Figure 3. In the case of aging at $725^{\circ} \mathrm{C}$, only the data after the peak in resistivity were fit, since this is the region where the $\eta^{\prime}$ model is valid. 

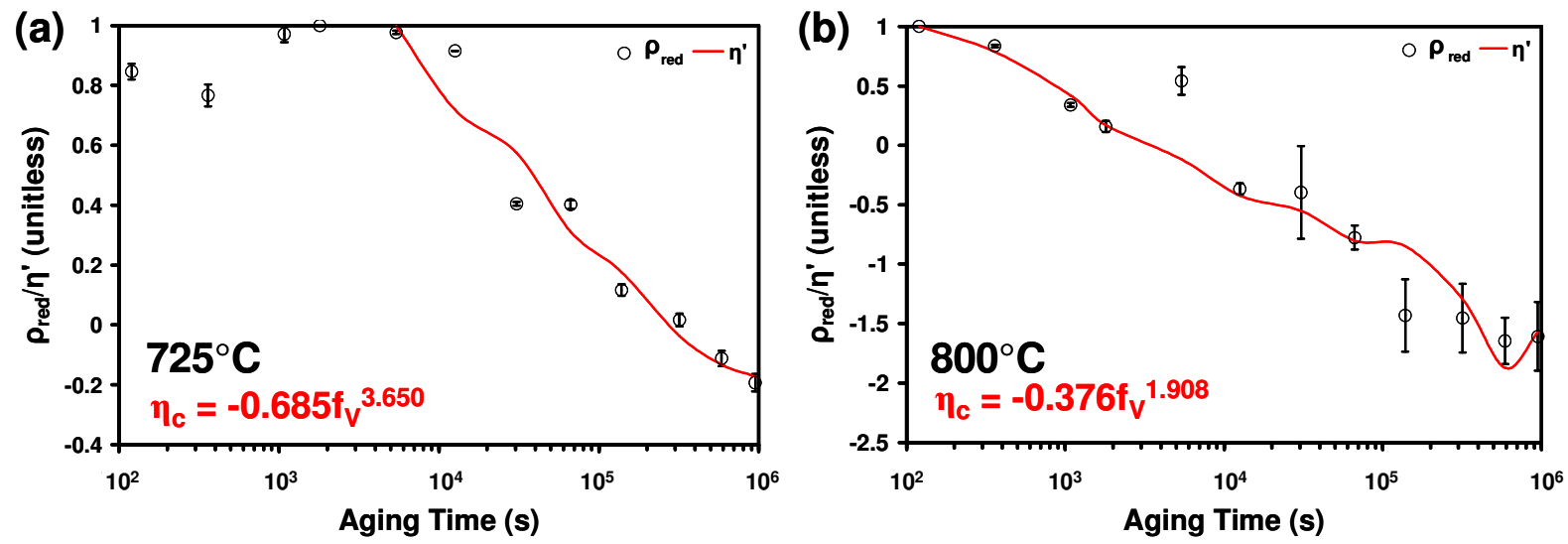

Figure 6. Reduced resistivity ( $\rho_{\text {red }}$ ) as a function of aging time for aging at (a) $725^{\circ} \mathrm{C}$ and (b) $800^{\circ} \mathrm{C}$. The data is fit with a microstructural model for the expected electrical behavior ( $\eta^{\prime}$ ) via non-linear least squares regression. The fitting parameters are included on the graphs.

The good fit of the $\eta$ ' model to the actual measured resistivity data shown in Figure 6 proves the validity of this microstructural model for predicting the electrical response in age hardened Waspaloy. With the exception of a few outliers (most notably the specimen aged at $800^{\circ} \mathrm{C}$ for $5.4 \times 10^{3} \mathrm{~s}$ ), the microstructural model clearly shows the same trends as the measured resistivity data. Further improvements to this model may include the effects of matrix strains (accompanied by an expected increase in dislocation density) and calculating the effect of the exact matrix composition and precipitate composition on the electrical response.

\section{Conclusions}

Small angle neutron scattering has proven to be an accurate, statistically significant, method of obtaining volume distributions of $\gamma^{\prime}$ precipitates in aged Waspaloy specimens. The average precipitate radii, derived from these volume distributions, increase progressively with both aging time and aging temperature. Electrical resistivity measurements for the aged Waspaloy specimens show an initial increase to a maximum at short aging times, followed by a decrease after the initial resistivity peak. The $\eta$ ' microstructural model shows a good fit to the measured electrical resistivity, indicating that this model and its corresponding assumptions are valid for predicting the electrical response in aged Waspaloy for aging times after the initial maximum in resistivity. The validity of the $\eta$ ' model also indicates the sensitivity of electrical resistivity measurements, to quantitative aspects of the $\gamma^{\prime}$ precipitate microstructure in nickel base superalloys.

\section{Acknowledgements}

The authors wish to acknowledge the funding for this work provided by the U.S. Department of Energy under grant number DE-FG 02-03-ER 46035. All SANS data was obtained at Oak Ridge National Laboratory's High Flux Isotope Reactor, sponsored by the Scientific User Facilities Division, Office of Basic Energy Sciences, U.S. Department of Energy. 


\section{References}

1 R. L. Whelchel, V. S. K. G. Kelekanjeri, and R. A. Gerhardt, "Mechanical and electrical characterisation in age hardened Waspaloy microstructures," International Heat Treatment and Surface Engineering, vol. 3, pp. 35-39, 2009.

2 V. S. K. G. Kelekanjeri, L. K. Moss, R. A. Gerhardt, and J. Ilavsky, "Quantification of the coarsening kinetics of $\gamma^{\prime}$ precipitates in Waspaloy microstructures with different prior homogenizing treatments," Acta Materialia, vol. 57, pp. 4658-4670, Sep 2009.

3 V. S. K. G. Kelekanjeri and R. A. Gerhardt, "Etch pit and $\gamma^{\prime}$ precipitate evolution in controlled Waspaloy microstructures aged at 725, 800 and $875^{\circ} \mathrm{C}, "$ Acta Materialia, vol. 57, pp. 616-627, Jan 2009.

$4 \quad$ R. L. Whelchel, V. S. K. G. Kelekanjeri, R. A. Gerhardt, and J. Ilavsky, "Effect of Aging Treatment on the Microstructure and Resistivity of a Nickel Base Superalloy," Metallurgical and Materials Transactions A, Submitted for Publication, 2010.

5 R. L. Whelchel, V. S. K. G. Kelekanjeri, R. A. Gerhardt, J. Ilavsky, and K. C. Littrell, "Correlating Small Angle Scattering Spectra to Electrical Resistivity Changes in a Nickel-Base Superalloy," in Materials Research Society Spring Meeting, San Francisco, CA, Document W10.5, 2010.

6 R. J. White, S. B. Fisher, K. M. Miller, and G. A. Swallow, "Resistometric Study of Aging in Nimonic Alloys (I). PE16," Journal of Nuclear Materials, vol. 52, pp. 51-58, 1974.

7 R. Ferragut, A. Somoza, and I. Torriani, "Pre-precipitation study in the 7012 Al-Zn-Mg$\mathrm{Cu}$ alloy by electrical resistivity," Materials Science and Engineering A-Structural Materials Properties Microstructure and Processing, vol. 334, pp. 1-5, Sep 2002.

8 D. Mukherji, D. Del Genovese, P. Strunz, R. Gilles, A. Wiedenmann, and J. Rosler, "Microstructural characterisation of a Ni-Fe-based superalloy by in situ small-angle neutron scattering measurements," Journal of Physics: Condensed Matter, vol. 20, pp. 104220-104228, 2008.

9 J. Zrnik, P. Strunz, P. Hornak, V. Vrchovinsky, and A. Wiedenmann, "Microstructural changes in long-time thermally exposed Ni-base superalloy studied by SANS," Applied Physics A, vol. 74, pp. S1155-S1157, 2002.

10 M. Sundararaman, W. Chen, R. P. Wahi, A. Wiedenmann, W. Wagner, and W. Petry, "TEM and SANS Investigation of Age Hardened Nimonic PE16 after Cyclic Loading at Room-Temperature," Acta Metallurgica Et Materialia, vol. 40, pp. 1023-1028, May 1992.

11 J. Ilavsky and P. R. Jemian, "Irena: tool suite for modeling and analysis of small-angle scattering," Journal of Applied Crystallography, vol. 42, pp. 347-353, Apr 2009. 
12 K. C. Littrell, Personal Communication.

13 V. S. K. G. Kelekanjeri and R. A. Gerhardt, "A closed-form solution for the computation of geometric correction factors for four-point resistivity measurements on cylindrical specimens," Measurement Science \& Technology, vol. 19, pp. 025701-025712, Feb 2008.

14 R. J. Roe, Methods of X-ray and neutron scattering in polymer science. New York :: Oxford University Press, 2000.

15 S. Chandrasekhar, "Stochastic problems in physics and astronomy," Reviews of Modern Physics, vol. 15, pp. 0001-0089, Jan 1943. 